\title{
Aspectos bioecológicos e genético-comportamentais envolvidos na conservação da abelha Jandaíra, Melipona subnitida Ducke (Apidae, Meliponini), e o uso de ferramentas moleculares nos estudos de diversidade
}

\author{
Bioecological and behavioral genetic aspects involved in the conservation of \\ the stingless bee Melipona subnitida Ducke (Apidae, Meliponini) and the use \\ of molecular tools in studies of diversity
}

\section{Geice Ribeiro da Silva', Fábia de Mello Pereira², Bruno de Almeida Souza², Maria Teresa do Rego Lopes², José Elivalto Guimarães Campelo ${ }^{3}$, Fábio Mendonça Diniz ${ }^{2 *}$}

| | | | | | | | | | | | | | | | | | | | | | | | | | | | | | | | | | | | | | | | | | | | | | | | | | | | | | | | | | | | | | | | | | | | | | | | | | | | | | | | | | | | | | | | | | | | | | | | | | | | | | | | | | | | | | | | | | | | | | | | | | | | | | | | | | | | | | | | | | | | | | | | | | | | | | | | | | | | | | | | | | | | | | | | | | | | | | | | | | | | | | | | | | | | | | | | | | | | | |

RESUMO: A abelha sem ferrão Melipona subnitida atualmente está presente em quase toda a região nordeste, em função da boa adaptabilidade ao semiárido nordestino e do potencial econômico-ecológico proporcionado pela produçáo de mel e pela polinizaçáo de cultivos em condiçôes de confinamento. Apesar disso, é uma espécie ameaçada devido a processos de degradaçáo ambiental, dentre os quais estão o desmatamento, o uso indiscriminado de agrotóxicos e o extrativismo. Tais interferências tendem a isolar as populaçóes de Jandaíra, provocando uma queda na variabilidade genética e, consequentemente, uma redução na capacidade adaptativa da espécie. Porém, técnicas de biologia molecular estão sendo implementadas, possibilitando que populaçôes desse tipo sejam avaliadas quanto ao seu grau de variabilidade genética. Marcadores moleculares do tipo microssatélites de DNA vêm sendo bastante usados, porém, em funçáo do alto custo exigido para seu desenvolvimento, diversos estudos vêm empregando microssatélites transferidos de táxons próximos com amplo sucesso em estudos voltados à caracterização e à diversidade genética. Dessa forma, a presente revisão objetivou avaliar os mais relevantes aspectos bioecológicos e genético-comportamentais envolvidos na conservação da abelha Jandaíra, a fim de auxiliar na avaliação do grau de diversidade genética da espécie, bem como da sua distribuição entre indivíduos e populaçôes da abelha sem ferrão M. subnitida.

PALAVRAS-CHAVE: abelha nativa; microssatélites; transferibilidade; diversidade genética, conservação.

\begin{abstract}
The stingless bee Melipona subnitida is now present almost everywhere in the Brazilian Northeastern, as a consequence of its good adaptability to the semiarid and economic and ecological potential offered by the honey production and pollination of commercial crops under confined conditions. Nevertheless, it is an endangered species due to environmental degradation processes, among which are: deforestation, indiscriminate use of pesticides and honey extraction. Such interference tends to isolate populations of Jandaíra causing a decrease in genetic variability, and therefore a reduction in the adaptive capacity of the species. However, advanced Molecular Biology techniques have been used allowing such populations to be assessed for their degree of genetic variability. Molecular markers such as microsatellite DNA are widely applied to genetic diversity studies. However, due to the high costs required for their development, several studies have been focused on the use of microsatellites transferred from closely related taxa with much success in studies on the genetic characterization of species and their populations. Therefore, this review aimed to evaluate the most relevant ecological and behavioral aspects in order to assist the population genetic studies of the stingless bee M. subnitida.
\end{abstract}

KEYWORDS: native bees; microsatellites; transferability; genetic diversity; conservation. 


\section{INTRODUÇÃO}

As abelhas são insetos pertencentes à ordem Hymenoptera, da superfamília Apoidea e subgrupo Anthophila (Michener, 2007; Camargo; Pedro, 2012). São conhecidos no mundo pelos vários benefícios que proporcionam, como a capacidade de algumas espécies de produzir mel e pelo seu papel natural de polinização (SAntos, 2010). Destes, a tribo Meliponini, caracterizada pela ausência do ferrão, destaca-se por possuir grande número de espécies distribuídas por todos os continentes, desde regiôes tropicais até o sul de regiôes subtropicais, estando a maior parte localizada no território Latino-americano. Estão presentes também em algumas regiôes temperadas. A tribo é dividida em 31 gêneros, com cinco deles baseados em fósseis (Creptotrigona Engel, Kelneriapis Sakagami, Liotrigonopsis Engel, Meliponorytes Tosi, e Proplebeia Michener (Michener, 2007; Camargo; Pedro, 2012).

No Brasil, o gênero Melipona Illiger (1806) tem ganhado respaldo em função do seu potencial econômico e ecológico, com destaque para a espécie Melipona subnitida Ducke (1910) (Jandaíra), devido à sua boa adaptação à regiáo semiárida (CÂmara et al., 2004). Porém, o constante desmatamento, somado ao extrativismo pelos meleiros, vem aumentando a pressão sobre este importante recurso natural, sendo necessário utilizar estratégias avançadas que auxiliem na sua conservação (SANTOS, 2010).

Os marcadores moleculares vêm sendo empregados como uma importante ferramenta na conservação de espécies selvagens e/ou de interesse econômico por fornecerem dados importantes aos estudos populacionais, como: estimativas referentes ao grau de variabilidade genética, grau de endogamia, diferenças entre populaçóes, fluxo gênico entre populaçôes, determinação do tamanho efetivo da população, dentre outros (Müller et al., 2010; TAVAREs et al., 2013). Dos marcadores disponíveis, os microssatélites, sequências de DNA curtas repetidas em tandem, são os mais usados devido ao grande volume de informaçóes fornecidas (Clementino et al., 2010). No entanto, o desenvolvimento desses marcadores é de alto custo e a técnica requer o emprego de métodos mais avançados da biologia (Francisco et al., 2013). Em função disso, diversos trabalhos vêm empregando marcadores desenvolvidos para espécies de táxons próximos, tendo por base a conservação das sequências adjacentes à regiáo de repetição. Estudos têm comprovado a eficácia de marcadores microssatélites transferidos, inclusive a partir de gêneros diferentes (Lopes et al., 2010; Alves et al., 2011; VIANA et al., 2011). Porém, para que se tenha uma avaliação genética adequada é necessário que se conheçam aspectos bioecológicos e comportamentais da espécie.

Desta forma, este artigo de revisão aborda alguns aspectos bioecológicos e genético-comportamentais que possam interferir significativamente na interpretação de resultados obtidos por meio do uso de marcadores microssatélites, tendo em vista a avaliaçáo do grau de diversidade genética da espécie, bem como sua distribuição entre indivíduos e populaçôes da abelha sem ferrão M. subnitida.

\section{Aspectos bioecológicos das abelhas do gênero Melipona}

Dentre as abelhas sem ferrão, o gênero Melipona compreende o de maior número em espécies no Brasil, destacando-se pela grande riqueza em biodiversidade (Silva; PAZ, 2012). No geral, apresenta distribuição neotropical, indo do México à Argentina, com cerca de 40 espécies catalogadas (Michener, 2007).

Seus ninhos são construídos tipicamente em cavidades de árvores nativas, sendo que o diâmetro interno varia de acordo com a espécie nidificada (Vossler, 2012).

Possui um nível de organização social altamente evoluído, com sobreposição de castas, e cada grupo de abelhas é responsável por um tipo de atividade dentro da colmeia (VILLAS-BôAs, 2012).

O gênero Melipona é o único táxon de Meliponini em que as células de cria são indiferenciadas, ou seja, células de rainha, machos e fêmeas são de tamanhos iguais. Como nos demais gêneros, seus ninhos são dispostos em placas concêntricas empilhadas na vertical, compostas de favos circulares constituídas por cerume (mistura de cera com resina vegetal), organizados basicamente em células de cria e potes de alimentos. Os potes de alimento são, em sua maioria, construídos na forma ovoide, armazenando separadamente mel e pólen (Fig. 1). A entrada é quase sempre no centro, construída basicamente de geoprópolis (argila e resinas vegetais), barro ou cera, apresentando-se de diversas formas conforme a espécie de abelha (Nogueira-Neto, 1997; VIllas-BôAs, 2012).

A rainha é responsável pela postura dos ovos e pela organização social do ninho, feita por meio dos ferormônios produzidos nas suas glândulas mandibulares. A determinaçáo da casta é genético-alimentar (Kerr et al., 1950; Kerr et al., 1966).

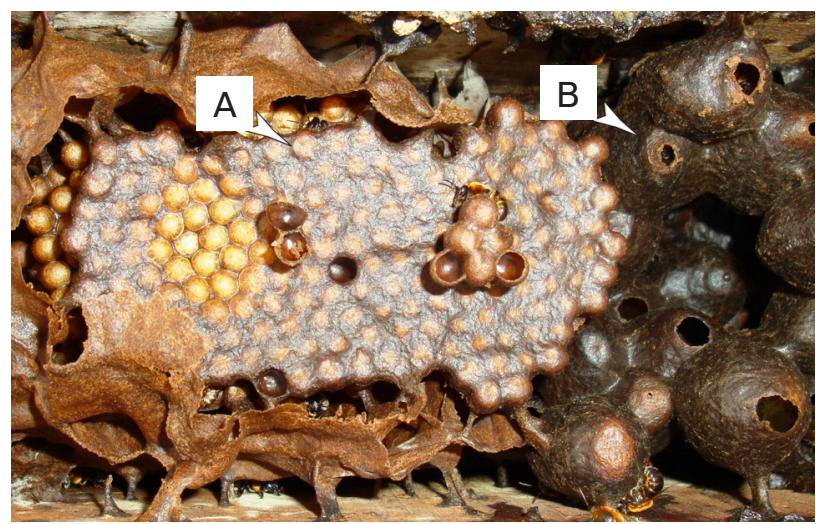

Figura 1. Colmeia de abelhas M. subnitida. (A) Favos de cria; (B) Potes de armazenamento de mel (Fonte: José Maria Vieira Neto). 
As fêmeas selecionadas possuem uma predisposição genética, com a expressão gênica influenciada pela alimentação, que pode diferenciar-se na quantidade e/ou na qualidade (Kerr et al., 1966; Jarau et al., 2010). Morfologicamente, diferenciam-se das outras fêmeas pelo tamanho desproporcional do perímetro abdominal em relação ao corpo e as asas (Fig. 2) o que as impossibilita de sair do ninho e realizar voos (Leimar et al., 2012).

Por sua vez, os zangóes têm como funçáo principal realizar a fecundação da rainha virgem, apesar de esporadicamente serem observados zangóes realizando trabalhos de manutenção da colmeia, tais como: desidratação do néctar e manipulação de cera (VILLAS-BôAS, 2012).

$\mathrm{Na}$ colmeia, as abelhas operárias são encarregadas pela maioria das atividades, o que depende, dentre outros fatores, da idade e das necessidades da colmeia (KerR et al., 1996; Nogueira-Neto, 1997). Em condiçōes normais, essas operárias realizam a postura de dois tipos de ovos: ovos reprodutivos, que se desenvolvem em machos; e ovos tróficos, que servem como alimento para a rainha (Cepeda-Aponte, 2003).

O ciclo de vida das Melipona gira em torno de seis dias para ovo, 12 dias para larva e 24 dias para pupa, totalizando 42 dias até a emergência do adulto (BRUENING, 2006). As abelhas operárias e os zangóes alcançam uma expectativa de vida por volta de 90 dias, e as rainhas, entre quatro e cinco anos (Bruening, 2006). Como insetos da ordem Hymenoptera, o sistema de determinação do sexo nos meliponíneos é haplodiploide, sendo que a maior parte das espécies apresenta fêmeas com células diploide, com $2 \mathrm{n}=18$ (oriundas de ovos fecundados), e os machos apresentam células haploide, com $\mathrm{n}=9$ (oriundos de ovos não fecundados). Em outros casos, por exemplo, Melipona seminigra, as fêmeas possuem $2 \mathrm{n}=22$, e os machos, $\mathrm{n}=11$ (TAVAres et al., 2010; Francini et al., 2011; TAVARES et al., 2012).

\section{Aspectos genético-comportamentais em abelhas sem ferrão}

As abelhas do gênero Melipona são especialmente sensíveis aos distúrbios causados ao meio ambiente, já que dependem das árvores para moradia e alimentação (BRUENING et al., 2006; Vossler, 2012). Com o processo de destruição das matas, o uso de agrotóxicos e o extrativismo dos meleiros (Santos, 2010), elas estáo cada vez mais ameaçadas, o que traz reflexos negativos sobre a biodiversidade e grandes prejuízos econômicos, pois com menos polinizadores a produçáo agrícola de plantas polinizadas tende a cair.

Em funçấo da impossibilidade do voo das rainhas fisogástricas (rainhas em intensa postura), as colônias não podem se deslocar em situaçôes de distúrbio. Além disso, o processo de dispersão natural dessas abelhas pode ser considerado lento,

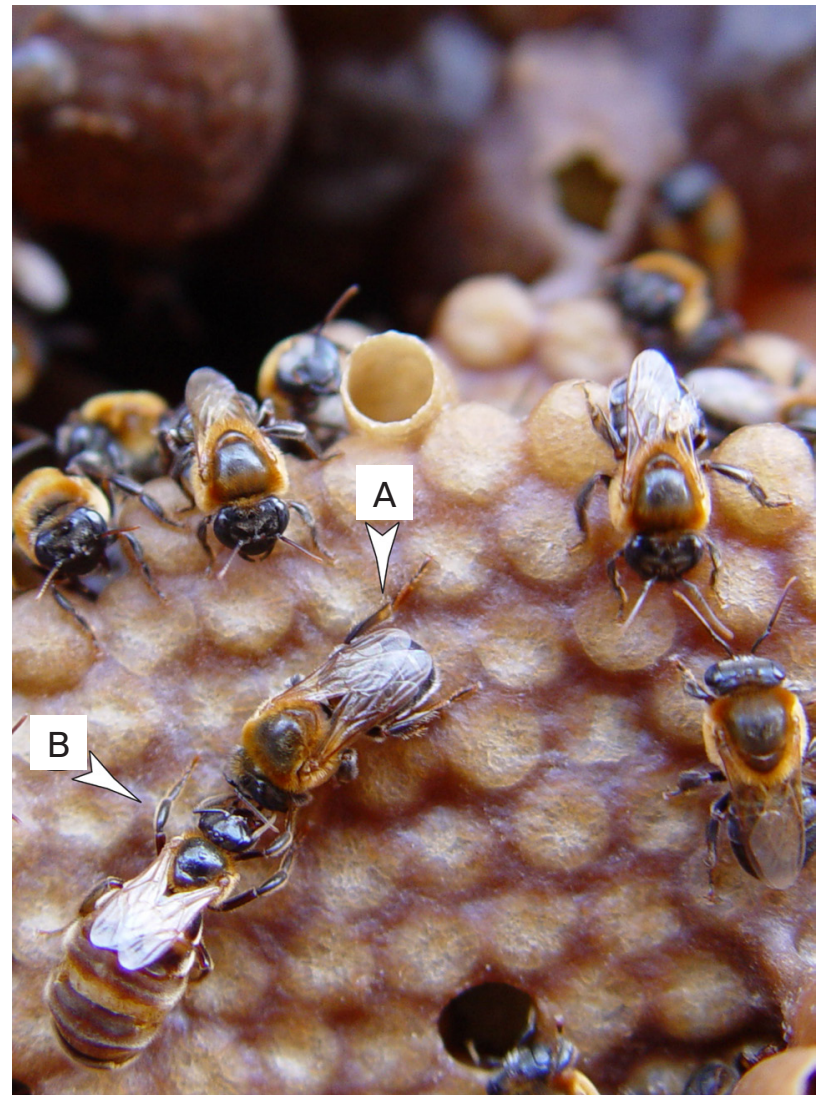

Figura 2. (A) Uma operária; (B) alimentando a rainha da colmeia (Fonte: José Maria Vieira Neto).

já que as novas colônias são fundadas a distâncias curtas da colônia mãe (Michener, 2007). Geralmente, a dispersão acontece no período de enxameação, época em que a colmeia está populosa. Nesse período, depois que as abelhas fazem a escolha do novo local de nidificação, a princesa (rainha virgem) sai com algumas dezenas de operárias (atraídas pelos ferormônios "reais") para o novo habitat. A colmeia é firmada quando a princesa realiza o voo nupcial e é fecundada pelo zangão (BRUENing, 2006). Esse processo de fundaçấo de uma nova colônia pode ter duração variável de 15 a 110 dias (Nogueira-Neto, 1997). Uma característica peculiar é que durante a enxameação, a nova colmeia depende exclusivamente da colmeia-mãe em relaçấo a materiais e alimentos, causando, portanto, a curta dispersão dos enxames, diferentemente das abelhas Apis mellifera (NogueIraNeto, 1997; Cronin et al., 2013). Tal comportamento tem influência direta na composição genética, uma vez que há menor possibilidade de fluxo gênico entre colônias distintas de locais distantes, diminuindo seu aporte genético (Nogueira-Neto, 1997).

Portanto, a baixa variação genética em conjunto com o pequeno tamanho efetivo da população tende, por consequência natural, a aumentar a deriva genética, causando uma possível perda de alelos importantes à sua adaptação. Isso leva 
naturalmente a uma menor flexibilidade adaptativa em relação, por exemplo, ao gênero Apis (FALCONER, 1987).

Sabe-se que, adaptativamente, algumas espécies passaram a adotar estratégias alternativas para sobrepor à baixa variação. Boa parte das que compóem o gênero Melipona possui certa porcentagem de operárias capazes de pôr ovos reprodutivos, os quais se desenvolvem em machos férteis (CEPEDA-APONTE, 2003). Isso assegura a adiçâo de mais uma possível fonte de contribuição para o patrimônio genético da espécie .

Outro comportamento é aquele observado na espécie Melipona bicolor Lepeletier (1836), que apresenta colônias em condiçóes de poliginia natural duradoura, com mais de uma rainha fisogástrica fazendo a postura dos ovos durante a vida útil da colmeia. Possivelmente, este é um comportamento que pode abranger muitos outros meliponíneos, uma vez que em espécies como M. quadriafasciata e $M$. scutellaris é possível observar ocasionalmente o uso de tal estratégia como forma alternativa de sobrevivência (Velthuis et al., 2006; CaRvalho et al., 2010; Alves et al., 2011; Carvalho et al., 2011).

Apesar da solução adaptativa encontrada por algumas espécies para contornar a baixa variação genética característica do grupo, ela ainda é bastante tímida frente à constante devastação das matas, o que contribui para uma eventual perda de estoques e causa o isolamento das populaçóes de abelhas. Pode haver um processo forçado de adaptaçôes genéticas e ecológicas devido à desestruturação provocada em seu habitat, agravando o quadro de perda de variabilidade genética e a consequente erosão genética (AvisE; НAMrick, I 996; Antonini et al., 2013).

Estudos com diferentes meliponíneos confirmam tal perturbação na constituição genética das populaçôes (CARVALHOZilse; Kerr, 2006; Pinto, 2007; Carvalho-Zilse et al., 2009). O que se percebe na maioria dos trabalhos é uma queda cada vez maior no número de alelos e heterozigotos em função da endogamia, influenciados pelo fluxo gênico restrito, uma vez que populaçóes distintas são interrompidas em cruzar genes entre si. Por consequência, isso aumenta a taxa de fixaçáo de genes, amplia o nível de estruturação genético-populacional e torna alguns alelos raros por ocasiáo da deriva genética (Carvalho-Zilse; Kerr, 2006; Carvalho-Zilse, et al., 2009).

Portanto, estratégias de manejo já consagradas auxiliam na conservação de espécies de abelhas sem ferrão, principalmente no que se refere ao aumento na taxa de diversidade genética, ocasionadas pelo aumento na recombinação genotípica e na heterozigosidade dos indivíduos nas diferentes colmeias.

Diante do exposto, é imprescindível que haja maior empenho de programas de conservação e mais incentivo na adoção de programas de melhoramento sustentável que incluam o pequeno agricultor dentro desse cenário desenvolvimentista com fins de ampliaçáo do mercado interno, gerando maior expectativa econômica e, consequentemente, preservando a biodiversidade e os recursos naturais necessários ao desenvolvimento.

\section{Melipona subnitida (Jandaíra Nordestina) e sua importância econômico-ambiental}

A Jandaíra, Melipona subnitida Ducke, foi registrada pela primeira vez no município de Alcântara, no Maranhão, com distribuição abrangendo "parte norte do nordeste seco do Brasil" (Ducke, 1910). Na década de 1970, foi registrada estendendo-se a partir do norte do rio São Francisco, sendo abundante no Rio Grande do Norte e no Ceará (GonçALVEs, 1973). Recentemente, sabe-se que está presente em praticamente todos os estados do Nordeste semiárido do Brasil, possivelmente devido ao aumento da comercializaçáo de suas colônias pelo nordeste e à facilidade de adaptaçáo a novos recursos florais (CÂmara et al., 2004; Bruening, 2006; Camargo; Pedro, 2012).

Apesar de serem bastante maleáveis com relação à nidificação, as espécies de plantas mais frequentes para moradia são a Imburana [Commiphora leptophloeos (Mart.) J. B. Gillett] e a Catingueira (Caesalpinia bracteosa Tul.) (CÂmara et al., 2004; BRuening, 2006).

É uma espécie de grande potencial econômico na região da Caatinga e, além de ter maior área de ocorrência, pode se adaptar às mais adversas situaçôes no meio, inclusive em condiçôes de confinamento (Freitas et al., 2000; Cruz et al., 2004). Trabalhos como o de CÂmara et al. (2004) relataram a grande importância desse tipo de abelha para a subsistência ou complemento financeiro à algumas famílias localizadas no meio rural do Rio Grande do Norte (Fig. 3).

Devido aos baixos custos de implantação, manejo simplificado, ausência de acidentes com ferroadas e baixo impacto ambiental, a meliponicultura (criaçáo racional de abelhas sem ferrão) vem crescendo bastante nos últimos anos. Alcançou grande importância não só na esfera econômica, mas também nas esferas cultural e ambiental, chegando ao patamar de tecnologia social, com capacidade de garantir livre acesso ao circuito formal do capital sem gerar, na produção, impacto negativo significante ao meio ambiente (Nogueira-Neto, 1997; Kerr et al., 2001; Teixeira, 2007; CaValCante et al., 2009).

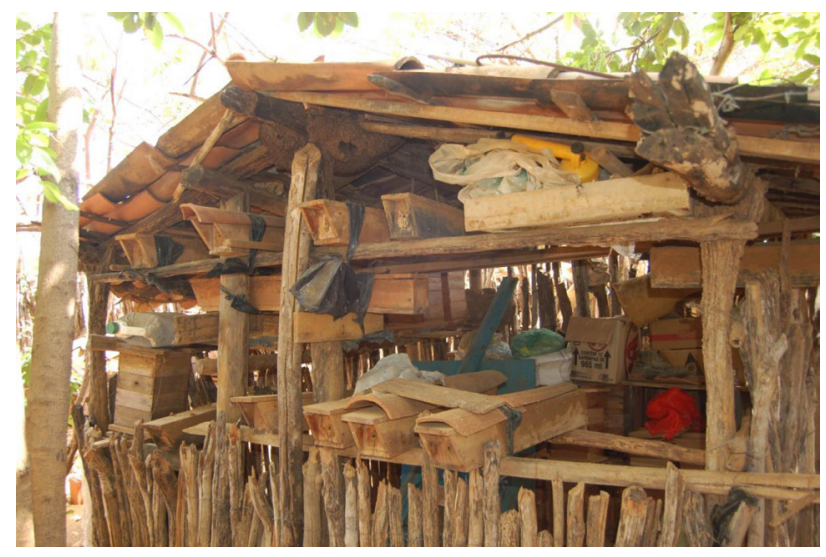

Figura 3. Meliponário da localidade Jucurí, município Mossoró (RN) (Fonte: Kalhil Pereira França). 
A atividade mais apreciada nessa espécie é a produção de mel, que tem grande valia para a população nordestina em função de suas características peculiares. Estas vão desde suas propriedades organolépticas até seu caráter medicinal, citado pela cultura popular, comprovado em nível científico na eficácia de melhora em cicatrizaçôes e combate antimicrobiano em ferimentos infecciosos (Alves et al., 2008).

Diante dos problemas de desmatamento, discute-se a ampliação da meliponicultura com vistas a corrigir problemas ambientais, com base no fato de as abelhas sem ferrão serem responsáveis pela polinização de grande parte da vegetação, cobrindo 40 a 90\% da vegetaçáo nativa (KerR et al., 1996; TeIXEIrA, 2007). Essa interação garante enorme sucesso na polinização cruzada, aumentando o vigor das espécies vegetais e flexibilidade adaptativa (Couto; Couto, 2002). Segundo TeIXEIRA (2007), sua criação contribui não só com a sua própria preservação, mas também com a da região em que está inserido, comprovando sua grande importância ambiental.

Pela alta flexibilidade adaptativa à exploração de diferentes tipos vegetais, recentemente muitos pesquisadores e criadores vêm demonstrando grande interesse na polinização de cultivares por parte das abelhas nativas. Esta atividade é realizada há muito tempo é em diversas partes do mundo (Freitas, 1998; Malagodi-Braga et al., 2000). Países como a Austrália concentram a meliponicultura na polinização de culturas comerciais, tais como noz macadâmia (Macadamia terifolia $\mathrm{F}$. Muell.), do que na produçáo de mel, movimentando uma parcela considerável da economia do país (HEARD; Exley, 1994; Dollin, 2000; Heard; Dollin, 2000).

No Brasil, Cruz et al. (2004) observaram uma grande vantagem em criar abelhas da espécie M. subnitida (Jandaíra), ao comprovarem boa adaptaçáo em casa de vegetação no cultivo de culturas de pimentão (Capsicum annum), uma vez que obtiveram frutos com bom ganho de peso, número de sementes e menor incidência de frutos com má formação. Além de outras peculiaridades, isso acontece devido ao fato de serem pouco agressivas e apresentarem menor amplitude de voo para forrageamento, tornando-as adequadas para a polinização em ambientes fechados (Cruz et al., 2004).

Apesar de não se saber da existência em M. subnitida, descobertas recentes apontam a melitocoria (capacidade de dispersão de sementes de determinadas espécies vegetais) como hábito que valoriza ainda mais o gênero e que pode ser explorado, adicionando um novo e valioso serviço para a manutençáo dos ecossistemas onde residem (Bacelar-Lima et al., 2006; Wallace; Trueman, 1995). No Brasil, isso foi observado pela primeira vez em abelhas $M$. seminigra merrillae $\mathrm{e}$. compressipes manaosensis, ao demonstrarem sua eficácia na dispersão de sementes de Zygia racemosa, "Angelim rajado" (BACELAR-Lima et al., 2006). Tal atuação acontece geralmente quando as abelhas coletam resina para a construção de colmeias, quando, por aderência, as sementes de algumas plantas resinosas sáo carregadas acidentalmente no corpo dos animais (Bacelar-Lima et al., 2006; Wallace; Trueman, 1995).

\section{Marcadores moleculares e a importância do uso dos marcadores microssatélites em abelhas sem ferrão}

$\mathrm{O}$ uso de marcadores moleculares baseados no DNA genômico é de fundamental importância como ferramenta avançada na estimativa de possíveis perturbaçōes causadas nas populaçôes naturais, mostrando não só a situação estrutural da composição genética, como também auxiliando programas de conservação e de melhoramento genético sustentável.

Anteriormente, tais estudos eram obtidos apenas com base no fenótipo dos organismos, sendo que eram utilizadas como marcadores genéticos algumas características variantes de herança mendeliana simples, a fim de possibilitar a inferência dos genótipos e monitorar a segregação do gene marcador; por consequência, era possível detectar variações no genoma (Regitano; Coutinho, 2001; Borém; CaIXeta, 2006). No entanto, o inconveniente dessa metodologia é que as variantes eram pouco frequentes nas populaçóes naturais, comportando-se, na maioria dos casos, como de caráter contínuo (Borém; CaIXeta, 2006). Porém, técnicas mais sofisticadas foram investigadas a fim de romper com essas barreiras, até que, em meados da década de 1980, surge uma série de marcadores baseados na amplificação de DNA in vitro (PCR - Reação em Cadeia de Polimerase), destacando-se hoje: RAPD (Random Amplified Polimorphic DNA), AFLP (Amplifield Fragments Lengths Polimorphic) e microssatélites.

Dentre estes, merecem destaque os microssatélites, que compreendem uma das mais poderosas ferramentas, com ampla popularidade no meio científico. Eles podem ser aplicados em diversas áreas, incluindo desde diagnósticos médicos até estudos de mapeamento genético, assim como como de genética populacional e conservaçáo (CLEMENTiNo et al., 2010). Dentro do genoma apresentam-se como curtas sequências de repetiçôes em tandem, que vão de um a seis nucleotídeos distribuídos aleatoriamente no genoma dos organismos eucarióticos (Schlötterer; Wiehe, 1999; Ellergreen et al., 2004). As principais vantagens que motivam seu uso estão relacionadas à riqueza de informaçóes fornecidas, dentre as quais estão as características de codominância, o fato de serem seletivamente neutros, altamente polimórficos e de apresentarem herança mendeliana (ELLERGREen $e t$ al., 2004).

Em abelhas, seu uso foi iniciado por Estoup et al. (1993). Ao desenvolverem os primeiros marcadores microssatélites para as espécies A. melifera e Bombus terrestris. Posteriormente, Rowe et al. (1997) desenvolveram mais 18 loci microssatélites para A. melifera, sendo que em sete deles obteve-se polimorfismo.

Com o trabalho de Peters et al. (1998), surgiram os primeiros marcadores para o gênero Melipona, no qual foram isolados e desenvolvidos primers para 25 loci da espécie $M$. bicolor, sendo 19 polimórficos. Dessa forma, serviram como ponto de partida para inúmeros trabalhos. 
Posteriormente, PAXTon et al. (1999) identificaram e desenharam primers de seis loci microssatélites em Scaptotrigona postiça, sendo que cinco deles demonstraram polimorfismo.

Já Green et al. (2001) obtiveram 10 loci em abelhas Trigona carbonaria, sendo que nove apresentaram-se polimórficos.

Recentemente, depois do surgimento dos primeiros marcadores oriundos da espécie $M$. bicolor (Peters et al., 1998), devido ao crescente volume de pesquisas voltadas a espécies de abelhas sem ferrão do gênero Melipona, houve a necessidade de desenvolver novos marcadores específicos, e até o momento há cinco disponíveis. Dentre eles, além de Peters et al. (1998), encontram-se os de Lopes et al. (2009), que identificaram 10 loci em $M$. rufiventris, obtendo 100\% de polimorfismo. Em 2010, os mesmos autores desenvolveram marcadores para a espécie $M$. mondury sequenciando 11 loci, sendo que nove deles demonstraram variaçôes. No mesmo período, Francini et al. (2009; 2010) desenvolveram loci para as espécies $M$. seminigra merrilae e $M$. interrupta manaosensis. Em M. seminigra merrilae obtiveram nove loci polimórficos de 15 desenvolvidos e, em $M$. interrupta manaosensis, obtiveram nove de 11 desenvolvidos.

Apesar disso, devido ao grande volume de espécies inerentes ao gênero e à escassez de estudos genéticos de espécies como a $M$. subnitida, o número de marcadores microssatélites ainda é irrisório, principalmente por ser um grupo caracterizado naturalmente pelo baixo nível de variabilidade genética em suas populaçóes. Uma das principais justificativas diz respeito à necessidade de conhecimento prévio da sequência, o que levaria à adoção de técnicas sofisticadas de isolamento e caracterização para cada espécie abordada, fato que exige altos custos em pesquisa (Francisco et al., 2013).

\section{O uso de marcadores microssatélites transferidos em abelhas sem ferrão}

Diante do exposto, alguns estudos têm demonstrado a conservação de sítios específicos, que flanqueiam sequências repetitivas entre espécies no mesmo gênero ou entre gêneros diferentes, o que torna possível transferir marcadores entre espécies ou gêneros usando primers heterólogos (Fig. 4), embora em alguns casos haja perda de conteúdo informativo em termos de variabilidade genética (ZANe et al., 2002; Fernandes et al., 2012).

Apesar disso, devido à escassez de informaçóes a respeito dos marcadores microssatélites para o gênero Melipona, diversos estudos com abelhas nativas vêm empregando este recurso. Um deles foi realizado por VIANA et al. (2011), os quais avaliaram a transferabilidade de 49 loci microssatélites desenvolvidos para M. bicolor (Peters et al., 1998), M. rufiventris (Lopes et al., 2009), M. mondury (Lopes et al., 2010), M. interrupta manaosensis (FRANCINI et al., 2010), M. seminigra merrillae (Francini et al., 2009) e Trigona carbonaria (GREEN et al., 2001) em quatro outras espécies do gênero Melipona (M. scutellaris, M. mondury, $M$. mandacaia e $M$. quadrifasciata). Os autores demonstraram, por meio da referida pesquisa, a possibilidade do uso dos marcadores heterólogos nas populaçóes testadas, ampliando, dessa forma, o número de loci a serem usados nos mais diversos estudos de cunho populacional.

No trabalho realizado por TAVAREs et al. (2007), que estudaram as populaçôes de $M$. rufiventris usando os primers oriundos da espécie $M$. bicolor, observou-se a importância informativa de tais marcadores, demonstrando que as açóes antrópicas referentes a manejo inadequado, direcionado a uma seleção pontual, estariam causando perturbaçóes na constituição genética de algumas populaçôes. Para dar mais veracidade aos dados, os autores tiveram o cuidado de confirmar os resultados gerados utilizando outros dois marcadores, o RAPD (Restriction Amplified Polimorphic DNA) e as aloenzimas para o mesmo conjunto de amostras.

Francisco et al. (2006), ao analisarem as populaçóes de Plebeia remota, Partamona mulata e Partamona helleri com primers heterólogos de $M$. bicolor, também demonstraram a utilidade dos marcadores heterólogos ao confirmarem a influência danosa da devastaçáo ambiental na diversidade genética das populaçóes selvagens de abelhas.

Apesar do exposto, algumas peculiaridades relacionadas à técnica de transferência de marcadores microssatélites não podem ser ignoradas, pois alguns trabalhos relatam a possibilidade de erros de genotipagem, que dependem principalmente

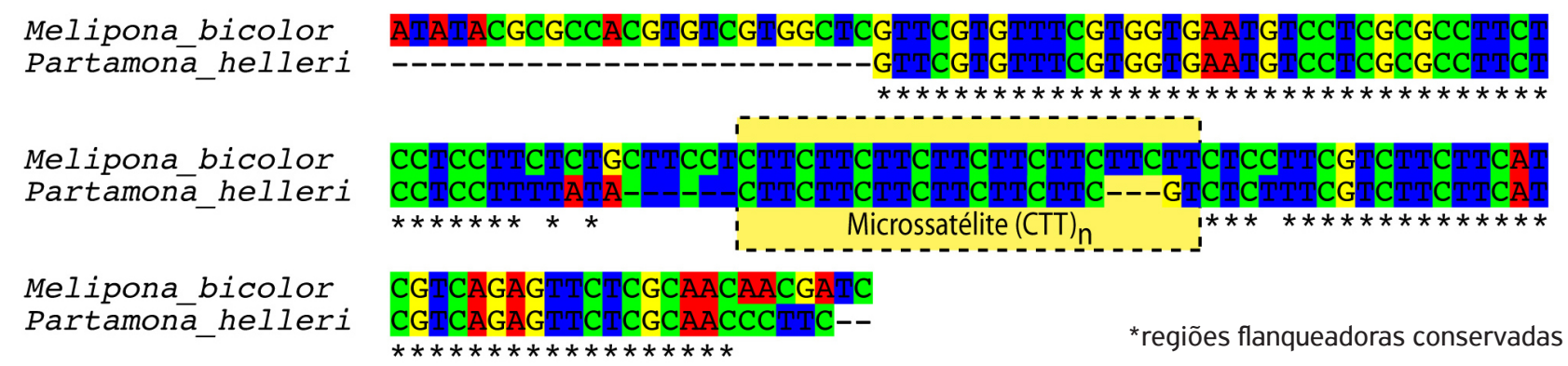

Figura 4. Conservação das sequências adjacentes à região de repetição (CTT)n em espécies de diferentes gêneros, Melipona bicolor (Genbank accession no.: AFO02846), e Partamona helleri (Genbank accession no.: AY866513), onde primers heterólogos podem ser desenhados para amplificação do mesmo locus em ambas as espécies. 
do distanciamento evolutivo entre as espécies (LOPEs et al., 2010; Fernandes et al., 2012).

Um dos problemas mais comuns observados na transferência de uma espécie para a outra se refere à persistência de alguns loci em fornecer informaçóes falsas a respeito do possível baixo polimorfismo, quando na verdade não há. Sabe-se que isso está relacionado ao aumento na presença de alelos nulos, fenômeno que ocorre com maior frequência em marcadores transferidos devido a mutaçóes naturais nas sequências flanqueadoras do loco microssatélite e que, por isso, não permite a ligação dos primers. Consequentemente, esses alelos não serão amplificados na reaçáo de $\mathrm{PCR}$, subestimando a heterosigosidade na população analisada e superestimando a diferenciação entre as populaçôes, mostrando, em alguns casos, a falsa impressão de baixo fluxo gênico (CALlen Et al., 1993; Chapuis; Estoup, 2007; Carvalho-Zilse et al., 2009).

Outro fator associado seria a presença de alelos homoplásicos ou em homoplasia de tamanhos, o qual estaria associado à amplificação de fragmentos diferentes e de mesmo tamanho, resultantes de mutaçôes convergentes (GARZA; Freimer, 1996; VIARD et al., 1998; Estoup et al., 2002). Foi demonstrado que tal fenômeno pode ocorrer tanto intra- como interpopulaçôes, mas que pode ser mais frequente entre geraçóes mais distantes taxonomicamente (GARZA; Freimer, 1996; Estoup et al., 2002). Em análises populacionais isso poderia gerar certo equivoco nas inferências, pois dois alelos idênticos em tamanhos e diferentes em sequência poderiam ser possivelmente confundidos como um único alelo (Esтоup et al., 2002). Em alguns casos, ainda pode haver a presença de alelos dropout, identificados pelo tamanho anormal do fragmento quando comparados com a média apresentada pela população. Esse fenômeno ocorre geralmente em função de um erro estocástico na amplificação, ligado, dentre outros fatores, possivelmente à qualidade do DNA extraído (NAVidi et al., 1992; TABerLet et al., 1996). Nesse caso, se o DNA extraído possui uma concentração muito baixa, então uma das cópias (materna ou paterna) terá a chance de ser mais amplificada do que a outra (Miller et al., 2002). Alguns trabalhos apontam o distanciamento evolutivo entre as espécies como fator adicional que tende a maximizar tal problemática, embora seja uma afirmação passível de mais estudos.

Mesmo assim, náo se pode deixar de observar a grande contribuição que os marcadores microssatélites transferidos estâo proporcionando para análise e/ou monitoramento populacional das abelhas sem ferrão, uma vez que, na maioria dos casos, muito do que é observado em campo corrobora com o verificado pelas informaçôes geradas pelos marcadores. No entanto, é uma técnica que requer certo cuidado na análise, principalmente na avaliação dos números de alelos e do grau de heterozigosidade, pois são parâmetros que podem variar, dependendo do caso (Lopes et al., 2010).

\section{CONSIDERAÇÕES FINAIS}

A conservação da espécie $M$. subnitida se torna evidente em função de sua fragilidade quanto às alteraçôes no meio ambiente. Em vista disso, a degradaçấo ambiental constante ameaça cada vez mais sua boa adaptabilidade ao semiárido nordestino, comprometendo seu potencial econômico-ecológico. A atençẫo dada atualmente reflete a preocupação em relação à diminuição deste recurso, uma vez que compreende importante fonte complementar de renda às famílias rurais, com capacidade de inclusão do pequeno agricultor no mercado interno, gerando, dessa forma, maior expectativa econômica. No entanto, há a necessidade de mais estudos em relação à espécie, principalmente quanto à situaçáo genética populacional vigente. Dessa forma, estudos de diversidade genética por meio de marcadores moleculares, tais como microssatélites, apresentam-se como importante ferramenta, a qual pode fornecer subsídios importantes para programas de conservação e melhoramento genético que garantam a preservaçáo de características referentes à adaptabilidade, necessárias ao uso adequado pela agricultura familiar e instituiçôes de pesquisa específicas.

\section{AGRADECIMENTOS}

Os autores são gratos ao Sr. José Maria Vieira-Neto pelo auxílio na coleta de campo. Este trabalho foi financiado pelo Banco do Nordeste do Brasil (BNB/ETENE/FUNDECI) e Embrapa (Macroprograma 2, SEG Code: 02.11.01.029.00.00). Agradecemos também a dois revisores anônimos, cujos comentários melhoraram significativamente a qualidade deste manuscrito.

\section{REFERÊNCIAS}

ALVES, D.A.; MENEZES, C.; IMPERATRIZ-FONSECA, V.L.; WENSELEERS, T. First discovery of a rare polygyne colony in the stingless bee Melipona quadrifasciata (Apidae, Meliponini). Apidologie, v.42, p.211-213, 2011.
ALVES, D.F.S.; CABRAL JUNIOR, F.C.; CÂMARA CABRAL, P.P.A.; OLIVEIRA JUNIOR, R.M.; REGO, A.C.M.; MEDEIROS, A.C. Efeitos da aplicação tópica do mel de Melipona subnitida em feridas infectadas de ratos. Revista Colégio Brasileiro de Cirurgiões, v.35, n.3, p.188-193, 2008. 
ANTONINI, Y.; MARTINS, R.P.; AGUIAR, L.M.; LOYOLA, R.D. RichnesS, composition and trophic niche of stingless bee assemblage in urban forest remnants. Urban Ecosystem, v. 16, p.527-541, 2013.

AVISE, J.C.; HAMRICK, J.L. Conservation genetics: case histories from nature. New York: Chapman \& Hall, 1996.

BACELAR-LIMA, C.G.; FREIRE, D.C.B.; COLETTO-SILVA, A.; COSTA, K.B.; LARAY, J.P.B.; VILLAS-BÔAS, H.C.; CARVALHO-ZILSE, G.A. Melitocoria de Zygia racemosa (Ducke) Barneby \& Grimes por Melipona seminigra merrillae Cockerell, 1919 and Melipona compressipes manaosensis Schwarz, 1932 (Hymenoptera, Meliponina) em la Amazônía Central, Brasil. Acta Amazonica, v.36, p.343-348, 2006.

BORÉM, A.; CAIXETA, E.T. Marcadores moleculares. Viçosa: Universidade Federal de Viçosa, 2006.

BRUENING, H.; Abelha Jandaíra. 3a ed. Natal: SEBRAE/ RN, 2006.

CALLEN, D.F.; THOMPSON, A.D; SHEN, Y.; PHILLIPS, H.A.; RICHARDS, R.I; MULLEY, J.C.; SUTHERLAND, G.R. Incidence and origin of "null" alleles in the $(A C)$ microsatellite markers. American Journal Human Genetic, v.52, p.922-927, 1993.

CÂMARA, J.Q.; SOUSA, A.H.S.; VASCONCELOS, W.E.; FREITAS, R.S.; MAIA, P.H.S.; ALMEIDA, J.C.; MARACAJÁ, P.B. Estudos de meliponineos com ênfase a Melipona subnitida D. no município de Jandaíra, RN. Revista de Biologia e Ciências da Terra, v.4, n. 1 (primer semestre), 2004.

CAMARGO, J.M.F.; PEDRO, S.R.M. Meliponini Lepeletier, 1836. In: MOURE, J.S.; URBAN, D.; MELO, G.A.R. (Orgs). Catalogue of Bees (Hymenoptera, Apoidea) in the Neotropical Region - online version, 2012. Disponível em: http://www.moure.cria.org.br/ catalogue. Acesso em 23 jan. 2014.

CARVALHO, C.A.L.; SANTOS, W.S.; NUNES, L.A.; SOUSA, B.A.; CARVALHO-ZILSE, G.A.; ALVES, R.M.O. Offspring analysis in a polygyne colony of Melipona scutellaris (Hymenoptera: Apidae) by means of morphometric analyses. Sociobiology, v.57, p.347-354, 2011.

CARVALHO, C.A.L.; SOUZA, B.A.; DIAS, C.S.; ALVES, R.M.O.; MELO, A.F.L.; SOARES, A.C.F.; CARVALHO-ZILSE, G.A. Five egg-laying queens in a single colony of Brazilian stingless bees (Melipona scutellaris Latreille). Acta Amazonica, v.40, p.123-126, 2010.

CARVALHO-ZILSE, G.A.; COSTA-PINTO, M.F.F.; NUNES-SILVA, C.G.; KERR, W.E. Does beekeeping reduce genetic variability in Melipona scutelaris (Apidae, Meliponinni)? Genetics and Molecular Research, v.8, n.2, p.758-765, 2009.

CARVALHO-ZILSE, G.A.; KERR, W.E. Utilização de marcadores microssatélites para estudos populacionais em Melipona scutellaris (Apidae, Meliponini). Magistra, v. 18, p.213-220, 2006.

CAVALCANTE, D.G.; MATOS, L.L.; PINHEIRO, E.S. Meliponicultura como fator de permanência do homem nas zonas de várzea do município de Boa Vista do Ramos/AM. In: XIX ENCONTRO NACIONAL DE GEOGRAFIA AGRÁRIA, São Paulo, p. 1-12, 2009.

CEPEDA-APONTE, O.I. Diferenciação do comportamento e fisiologia de operárias em Melipona bicolor (Apidae, Meliponinae). 2003. 209f. Tese (Doutorado - Ciências) - Instituto de Biociências, Universidade de São Paulo, São Paulo, 2003.
CHAPUIS, M.P.; ESTOUP, A. Microsatellite null alleles and estimation of population differentiation. Molecular Biology and Evolution, v.24, n.3, p.621-631, 2007.

CLEMENTINO, C.S.; BARBOSA, F.J.V.; CARVALHO, A.M.F.; COSTA-FILHO, R.A.R.; SILVA, G.R.; CAMPELO, E.G.; BRITTO, F.B.; DINIZ, F.M. Microsatellite DNA loci for population studies in Brazilian chicken ecotypes. International Journal Poultry Science, v.9, p.1100-1106, 2010.

COUTO, R.H.N.; COUTO, L.A. Apicultura: manejo e produtos. 2a ed. Jaboticabal: FUNEP, 2002. 191p.

CRONIN, A.D.; MOLET, M.; DOUMS, C.; MONININ, T.; PEETERS, C. Dependent colony foundation across eusocial insects. The Annual Review of Entomology, v.58, p.37-55, 2013.

CRUZ, D.O.; FREITAS, B.M.; SILVA, L.A.; SILVA, E.M.S.; BOMFIM, I.G.A. Adaptação e comportamento de pastejo da abelha Jandaíra (Melipona subnitida Ducke) em ambiente protegido. Acta Scientiarum. Animal Sciences, v.26, p.293-298, 2004

DOLLIN, A.E. Tips on stingless beekeeping by Australian beekeepers. Sydney: Australian Native Bee Research Centre, 2000.

DUCKE, A. Contribution a connaissance de la faune hymenoptérologique du Nord-Est du Brésil. Revue d'Entomologie, Caen. p.28-92, 1910.

ELLERGREEN, H. Microsatellites: simple sequence with complex evolution. Nature review: Genetics, v.5, p.435-445, 2004.

ESTOUP, A.; JARNE, P.; COURNET, J.M. Homoplasy and mutation model at microsatellite loci and their consequence for population genetics analysis. Molecular Ecology. v.1 1, p.1591-1604, 2002.

ESTOUP, A.; SOLIGNAC, M.; HARRY, H.; CORNUET, J.M. Characterization of (GT)n and (CT)n microsatellites in two insects species: Apis mellifera and Bombus terrestris. Nucleic Acids Research, v 21, p.1427-1431, 1993.

FALCONER, D.S. Introdução à genética quantitativa. Tradução de Martinho de Almeida e Silva e José Carlos Silva. Viçosa: UFV, 1987. 279p.

FERNANDES, C.R.M.; MARTINS, C.F.; FERREIRA, K.M.; DEL-LAMA, M.A. Gene variation, population differentiation and sociogenetic structure of nests of Partamona seridoensis (Hymenoptera: Apidae, Meliponini). Biochemical Genetics, v.50, p.325-335, 2012.

FRANCINI, I.B.; SFORÇA, D.A.; SOUSA, A.C.B.; CAMPOS, T.; CIDADE, F.W.; ZUCCHI, M.I.; SOUZA, A.P.; NUNES-SILVA, C.G.; CARVALHOZILSE, G.A. Microsatellite loci for an endemic stingless bee Melipona seminigra merrillae (Apidae, Meliponini) from Amazon. Conservation Genetics Resources, v.1, p.487-490, 2009.

FRANCINI, I.B.; SOUSA, A.C.B.; SFORÇA, D.A.; COSTA-PINTO, M.F.F.; CAMPOS, T.; NUNES-SILVA, C.G.; ZUCCHI, M.I.; SOUZA, A.P.; CARVALHO-ZILSE, G.A. Isolation and characterization of microsatellite loci in the stingless bee Melipona interrupta manaosensis (Apidae: Meliponini). Conservation Genetics Resources, v.2, p.27-30, 2010. 
FRANCINI, I.B.; GROSS, M.C.; NUNES-SILVA, C.G.; CARVALHO-ZILSE, G.A. Cytogenetic analysis of the Amazon stingless bee Melipona seminigra merrillae reveals different chromosome number for the genus. Scientia Agricola, v.68, n.5, p.592-593, 2011.

FRANCISCO, F.O.; DOMINGUES-YAMADA, A.M.T.; GONÇALVES, P.H.P.; BRITO, R.M.; PIOKER, F.C.; MATEUS, S.; ARIAS, M.C. Characterization of microsatellite loci for the stingless bee Scaura latitarsis (Hymenoptera: Apidae, Meliponini). Journal of Hymenoptera Research, v.30, p.7-11, 2013.

FRANCISCO, F.O.; BRITO, R.M.; ARIAS, M.C. Allele number and heterozygosity for microsatellite loci in different stingless bee species (Hymenoptera, Apidae, Meliponini). Neotropical Entomology, v.35, p.638-643, 2006.

FREITAS, B.M. Uso de programas racionais de polinização em áreas agrícolas. Mensagem Doce, n.46, 1998.

FREITAS, M.F.; MARINHO, I.V.; GUILHERME, R.F.; CALDAS, A.L. Preservação de Abelha Sem Ferrão no Semiárido Através da Criação Racional. Anais Do Encontro Paraibano De Educação Ambiental, João Pessoa, 2000, João Pessoa - PB.

GARZA, J.C.; FREIMER, N.B. Homoplasy for size at microsatellite loci in humans and chimpanzees. Genome Research, v,6, p.211217,1996

GONÇALVES, J.A. Ocorrência e abundância de abelhas indígenas no Estado do Ceará (Brasil). Fortaleza: Coleção Cearense de Agronomia. Junho, p.1-13, 1973.

GREEN, C.L.; FRANCK, P.; OLDROYD, B.P. Characterization of microsatellite loci for Trigona carbonaria, a stingless bee endemic to Australia. Molecular Ecology, v. 1, p.89-92, 2001.

HEARD, T.A.; EXLEY, E.M. Diversity, abundance and distribution of insect visitors to macadamia flowers. Environmental Entomology, v.23, p.91-100, 1994.

HEARD, T.A.; DOLLIN, A.E. Stingless bee keeping in Australia: snapshot of an infant industry. Bee World, v.81, p.116-125, 2000

JARAU, S.; VEEN, J.W.V.; TWELE, R.; REICHLE, C.; GONZALES, E.H.; AGUILAR, I.; FRANKE, W.; AYASSE, M. Workers make the queens in Melipona bees: Identification of geraniol as a caste determining compound from labial glands of nurse bees. Journal Chemistry Ecology, v.36, p.565-569, 2010.

KERR, W.E. Biologia e manejo da tiúba: a abelha do Maranhão. 156f. Dissertação (Mestrado) - Universidade Federal do Maranhão, 1996.

KERR, W.E. Genetic determination of castes in the genus Melipona. Genetics, v.35, p.143-152, 1950.

KERR, W.E.; CARVALHO, G.A.; SILVA, A.C.; ASSIS, M.G.P. Aspectos pouco mencionados da biodiversidade amazônica. Parcerias Estratégicas, v.12, p.20-41, 2001.

KERR, W.E.; STORT, A.C.; MONTENEGRO, M.J. Importância de alguns fatores ambientais na determinação das castas do gênero Melipona. Anais da Academia Brasileira de Ciências. v.38, p. 149-168, 1966.
LEIMAR, O.; HARTFELDER, K.; LAUBICHLER, M.D.; PAGE-Jr, R.E. Development and evolution of caste dimorphism in honeybees a modeling approach. Ecology and Evolution, v.2, p.3098-3109, 2012.

LOPES, D.M.; CAMPOS, L.A.O.; SALOMÃO, T.M.F.; TAVARES, M.G. Comparative study on the use of specific and heterologous microsatellites primers in the stingless bees Melipona rufiventris and M. mondury (Hymenoptera, Apidae). Genetics and Molecular Biology, v.33, p.390-393, 2010.

LOPES, D.M.; SILVA, F.O.D.; SALOMAO, T.M.F.; CAMPOS, L.A.D.O.; TAVARES, M.G. Microsatellite loci for the stingless bee Melipona rufiventris (Hymenoptera: Apidae), Molecular Ecology Resources, v.9, p.923-925, 2009.

MALAGODI-BRAGA, K.S.; KLEINERT, A.M.P.; IMPERATRIZ-FONSECA V.L. Stingless bees: greenhouse pollination and meliponiculture. Bitondi, M. M. and K. Hartfelder, editors. Anais do IV encontro sobre abelhas, Riberão Preto, Brasil, p. 145-150, 2000.

MICHENER, C.D. The Bees of The World. $2^{\mathrm{a}}$ ed. Baltimore, MD: Johns Hopkins University Press. 2007.

MILLER, C.R.; JOYCE, P.; WAITS, L.P. Assessing allelic dropout and genotype reliability using maximum likelihood. Genetics, v.160, p.357-366, 2002

MÜLLER, G.A.; MARCONDES, C.B.; NAVARRO-SILVA, M.A. Aplicações de marcadores microssatélites para o estudo de Culicidae (Diptera): revisão com especial referência a Haemagogus. Boletín de Malariología y Salude Ambiental, v.02, p.175-186, 2010.

NAVIDI, W.; ARNHEIM, N.; WATERMAN, M.S. A multiple tubes approach for accurate genotyping of very small DNA samples by using PCR: statistical considerations. American Journal Human Genetic, v50, p.347-359, 1992.

NOGUEIRA-NETO, P. Vida e criação de abelhas indígenas sem ferrão. São Paulo: Editora Nogueirapis, 1997. 446p.

PAXTON, R.J.; WEIBSCHUH, N.; ENGELS, W.; HARTFELDER, K.; QUEZADA-EUÁN, J.J.G. Not only single mating in stingless bees. Naturwissenschaften, v.86, p.143-146, 1999.

PETERS, J.M.; QUELLER, D.C.; IMPERATRIZ-FONSECA, V.L.; STRASSMANN, J.E. Microsatellite loci for stingless bees. Molecular Ecology, v.7, p.783-792, 1998.

PINTO, M.F.F.C. Caracterização dos locos microssatélites em duas espécies de abelhas da região Amazônica: Melípona compressipes e Melípona seminigra (Hymenoptera ; Apidae; Meliponina). $66 \mathrm{f}$. Dissertação (Mestrado em Ciências Biológicas), Universidade Federal do Amazonas, Manaus, 2007.

REGITANO, L.C.A.; COUTINHO, L.L. Biologia molecular aplicado à produção animal. Brasilia: Embrapa Informação Tecnológica, 2001, 215p.

ROWE, D.J.; RINDERER, T.E.; STELZER, J.A.; OLDROYD, B.P.; CROZIER, R.H. Seven polymorphic microsatellite loci in honeybees (Apis mellifera). Insect sociaux, v.44, p.85-93, 1997. 
SANTOS, A.B. Abelhas nativas: polinizadores em declínio. Natureza online, v.8, p.103-106, 2010.

SCHLÖTTERER, C.; WIEHE, T. Microsatellites, a neutral marker to infer selective sweeps, p.238-248. In: GOLDSTEIN, D.B.; SCHLÖTTERER, C. (Eds.). Microsatellites: Evolution and applications. New York: Oxford University Press, 1999, 368p.

SILVA, W.P.; PAZ, J.R.L. Abelhas sem ferrão: muito mais do que uma importância econômica. Natureza online, v.10, p. 146-152, 2012

TABERLET, P.; FRIFFIN, S.; GOOSSENS, B.; QUESTIAU, S.; MANCEAU, V. Reliable genotyping of samples with very low DNA quantities using PCR. Nucleic Acids Research, v.24, n.3189-3194, 1996.

TAVARES, G.M.; CARVALHO, C.R.; SOARES, F.A.F Genome size variation in Melipona species (Hymenoptera: Apidae) and subgrouping by their DNA content. Apidologie, v.41, p.636-642, 2010.

TAVARES, M.G.; CARVALHO, C.R.; SOARES, F.A.F.; CAMPOS, A.O. Genome size diversity in stingless bees (Hymenoptera: Apidae, Meliponini). Apidologie, v.43, p.731-736, 2012.

TAVARES, M.G.; DIAS, L.A.S.; BORGES, A.A.; LOPES, D.M.; BUSSE, A.H.P.; COSTA, R.G.; FERNANDES-SALOMÃO, T.M.; CAMPOS, L.A.O. Genetics divergence between population of the stingless bee uruçu amarela (Melipona rufiventris group, Hymenoptera, Meliponini): Is there a new Melipona species in the Brazilian state of Minas Gerais? Genetics and Molecular Biology, v.30, p.667-675, 2007.

TAVARES, M.G.; PIETRANI, N.T.; DURVALE, M.C.; RESENDE, H.C.; CAMPOS, L.A.O. Genetic divergence between Melipona quadrifasciata Lepeletier (Hymenoptera, apidae) populations. Genetics and Molecular Biology, v.36, p.111-117, 2013.
TEIXEIRA, A.F. Princípios agroecológicos aplicados à criação de abelhas nativas sem ferrão. Revista Brasileira de Agroecologia, v.2, n.2, p.1295-1298, 2007.

VELTHUIS, H.H.W.; DE VRIES, H.; IMPERATRIZ-FONSECA, V.L. The polygyny of Melipona bicolor: scramble competition among queens. Apidologie, v.37, p.222-239, 2006.

VIANA, M.V.C.; MIRANDA, E.A.; FRANCISCO, A.K.; CARVALHO, C.A.L.; WALDSCHMIDT, A.M. Transferability of microsatellite primers developed for stingless bees to four other species of genus Melipona, Genetics and Molecular Research, v.10, p.3942-3947, 2011.

VIARD, F.; FRANCK, P.; DUBOIS, M.P.; ESTOUP, A.; JARNE, P. Variation of microsatellite size homoplasy across electromorphs, loci, and populations in three invertebrate species. Journal of Molecular Evolution, v.47, p.42-51, 1998.

VILLAS-BÔAS, J. Manual Tecnológico: Mel de abelhas sem ferrão. Brasilia: Instituto Sociedade, população e Natureza (ISPN), Brasil, 2012.

VOSSLER, G.G. Flower visits, nesting and nest defence behaviour of stingless bees (Apidae: Meliponini): suitability of bee species for meliponiculture in the Argentinean Chaco region. Apidologie, v.43, p.139-161, 2012.

WALLACE, H.M.; TRUEMAN, S.J. Dispersal of Eucalyptus torelliana seeds by the resin-collecting stingless bee, Trigona carbonaria. Oecologia, v.104, p.12-16, 1995.

ZANE, L.; BARGELLONI, L.; PATARNELLO, T. Strategies for microsatellite isolation: a review. Molecular Ecology, v.11, n. 1 , p. 1-16, 2002. 